\title{
The Innovative Medicines Initiative launches call on Ebola and other filoviral haemorrhagic fevers
}

Eurosurveillance editorial team (eurosurveillance@ecdc.europa.eu) ${ }^{1}$

1. European Centre for Disease Prevention and Control (ECDC) Stockholm, Sweden

Citation style for this article:

Eurosurveillance editorial team. The Innovative Medicines Initiative launches call on Ebola and other filoviral haemorrhagic fevers. Euro Surveill.

2014;19(45):pii=20960. Available online: http://www.eurosurveillance.org/ViewArticle.aspx?Articleld=20960

Article published on 13 November 2014

On 6 November 2014, the Innovative Medicines Initiative 2 Joint Undertaking (IMI2 JU) [1] launched its second Call for Proposals in the framework of the IMI2 'Ebola and other filoviral haemorrhagic fevers programme (the Ebola+ programme)' [2]. Submissions for the Call can be made as of 22 November and closes on 1 December, and has an indicative budget of $€ 140$ million.

The following topics are covered in the Call for proposals:

Topic 1: Vaccine development Phase I, II, and III

Topic 2: Manufacturing capability

Topic 3: Stability of vaccines during transport and storage Topic 4: Deployment and compliance of vaccination regimens Topic 5: Rapid diagnostic tests

The Call and its topics will be further explained in a 17 November webinar.

The IMI is a public-private partnership, between the European Union and the European pharmaceutical industry, represented by the European Federation of Pharmaceutical Industries and Associations (EFPIA) in the life sciences area and launched in the year 2008. For the period 2014 to 2024, its budget is $€ 3.3$ billion. It has 46 projects running, some of which focus on challenges in drug development such as drug and vaccine safety, antimicrobial resistance and creating European platform to discover novel medicines. Others projects target specific health issues, e.g. diabetes, lung disease, oncology, inflammation and infection, and tuberculosis.

For more information about the Call and the IMI, read here: http://www.imi.europa.eu/sites/default/files/uploads/documents/IMI2Call2/IMI2_Call2_Text_FINAL.pdf.

\section{References}

1. The Council Regulation (EU) No 557/2014 of 6 May 2014 establishing the Innovative Medicines Initiative 2 Joint Undertaking. Official Journal L 169, 7.6.2014, p. 54-76. Available from: http://eur-lex.europa.eu/legal-content/EN/TXT /?uri=uriserv:OJ.L_.2014.169.01.0054.01.ENG

2. Innovative Medicines Initiative. Internet. Available from: http://www.imi.europa.eu/content/imi-2-call-2-o 